\title{
Crystal Structures and Phase Relationships of 2 Polymorphs of 1,4-Diazabicyclo[3.2.2]nonane-4-Carboxylic Acid 4-Bromophenyl Ester Fumarate, A Selective $\alpha-7$ Nicotinic Receptor Partial Agonist.
}

\author{
Benoît ROBERT ${ }^{1,2}$, Marc-Antoine PERRIN ${ }^{2}$, Maria BARRIO ${ }^{3}$, Josep-Lluis TAMARIT ${ }^{3}$, \\ Gérard COQUEREL ${ }^{1}$, René CEOLIN ${ }^{4}$, Ivo B. RIETVELD ${ }^{4 *}$ \\ ${ }^{1}$ Laboratoire Sciences et Méthodes Séparatives, UPRES EA 3233, Université de Rouen, \\ 1 rue Lucien Tesnière. F-76821 Mont Saint Aignan.
}

${ }^{2}$ Sanofi R\&D, Lead Generation \& Compound Realization/Analytical Sciences/Solid State group.

13 quai Jules Guesde. F-94400 Vitry sur Seine.

${ }^{3}$ Grup de Caracterització de Materials (GCM), Departament de Física i Enginyeria Nuclear, Universitat Politècnica de Catalunya, ETSEIB,

Diagonal 647. 08028 Barcelona, Spain.

${ }^{4}$ Caractérisation des Matériaux à Activité Thérapeutique (CAMMAT). Faculté de Pharmacie de l'université Paris Descartes,

4 avenue de l'observatoire. F-75006 Paris.

* Corresponding author

Keywords: API, polymorphism, topological phase diagram, Clapeyron equation, crystal structure, high pressure, thermal analysis, thermodynamics, stability

\begin{abstract}
Two polymorphs of the 1:1 fumarate salt of 1,4-diaza-bicyclo[3.2.2]nonane-4-carboxylic acid 4-bromo-phenyl ester, developed for the treatment of cognitive symptoms of schizophrenia and Alzheimer disease, have been characterized in the solid state crystallographically and thermodynamically. The relative stabilities have been inferred from experimental and topological P-T diagrams that show an overall enantiotropic relationship between forms I and II although no solid-solid transition was observed. The $\mathrm{dP} / \mathrm{dT}$ slope of the I-II equilibrium line in the P-T diagram is found to be negative and Form II is the stable phase up to about $371 \mathrm{~K}$, temperature at which the sublimation curves cross.
\end{abstract}

\section{Introduction}

According to Biton et al [1] and Pichat et al [2], compound SSR180711, 1,4-diazabicyclo[3.2.2]nonane-4-carboxylic acid 4-bromo-phenyl ester, is "a selective alpha 7 nicotinic receptor partial agonist, characterized as a promising new agent for the treatment of cognitive symptoms of schizophrenia with antidepressant-like properties...", and also for the treatment of Alzheimer disease. It has been developed and obtained by Sanofi-Aventis 
research departments as a fumarate salt of medicinal grade with the 1:1 stoichiometry (Figure $1)$.

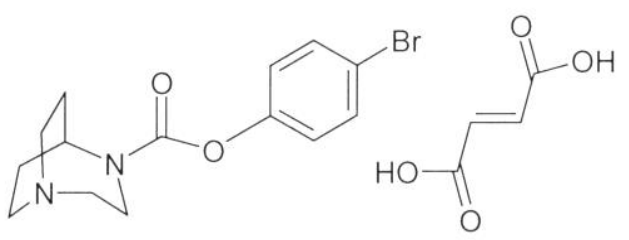

Figure 1. Chemical formula of SSR18077C. $\mathrm{C}_{14} \mathrm{H}_{17} \mathrm{BrN}_{2} \mathrm{O}_{2} \cdot \mathrm{C}_{4} \mathrm{H}_{4} \mathrm{O}_{4}, \mathrm{M}=441.27$ g.mol ${ }^{-1}$.

Two crystalline forms of SSR18077C were obtained through a polymorph screening, depending on which solvent and/or method were used (see Table 1). Anticipating the results on the stability hierarchy, the initial crystalline form will be named form I and the new form will be named form II.

\begin{tabular}{|l|l|l|}
\hline $\begin{array}{l}\text { Solvent used to obtain } \\
\text { a saturated solution }\end{array}$ & $\begin{array}{l}\text { Evaporation of the saturated } \\
\text { solution at room temperature }\end{array}$ & $\begin{array}{l}\text { Slow cooling from room } \\
\text { temperature to } 5^{\circ} \mathrm{C}\end{array}$ \\
\hline Water & Form II & Form II \\
\hline Methanol & Form II & Form II \\
\hline ethanol & Form I & Form I \\
\hline Acetone & Form I & Form II \\
\hline Acetonitrile & Form I & Form II \\
\hline Tetrahydrofurane & Form I & Form I \\
\hline Dioxane & Form I & Form II \\
\hline ethyl ether & Form I & Form II \\
\hline
\end{tabular}

Table 1.Results of the SSR18077C polymorph screening.

Therefore, studies were undertaken to fully characterize each form in the crystalline state and define the thermodynamic conditions of their relative stablilities.

The results are presented in the following.

\section{Methods}

\section{X-Ray Single Crystal Diffraction (XRSCD)}

XRSCD data were recorded on a Bruker Smart Apex single crystal diffractometer. A molybdenum I $\mu \mathrm{S}$ microfocus X-ray source was used, running at $50 \mathrm{kV}$ and $0.6 \mathrm{~mA}$, emitting Mo-K $\alpha$ radiation $(\lambda=0.710731 \AA$ ). A Charge-Coupled Device (CCD chip: $4 \mathrm{~K}, 62$ $\mathrm{mm}$ ) area detector was positioned at $6.0 \mathrm{~cm}$. The crystals were each mounted from a Paratone $\mathrm{N}^{\mathrm{TM}}$ oil drop onto a low background mylar MiTeGen loop. A full Ewald sphere of reflections was collected ( 3 omega scans of 680 frames with a frame width of $0.3^{\circ}$ ). Accumulation time for Form 1 and Form 2 was respectively 100 and 80 seconds for each frame.

For Form 1 -a non-merohedral twin- the orientation matrix and unit cell were established using CELL_NOW (v2008/4) program [3-1]. The 3D reflection profile and the integration of all reflections were carried out with the SAINT (v8.34A) program [42]. The TWINABS (v2012/1) program [5-3] was used to correct for Lorentz and 
polarization effects and for absorption due to the sample; In addition both HKLF4 and HKLF5 data were generated to respectively solve and refine with SHELXTL (v2014/7) program suite [4-2].

For Form 2 the orientation matrix and unit cell were established using the Apex2 (v2014.11-0) program suite [4-2]. The 3D reflection profile and the integration of all reflections were carried out with the SAINT (v8.34A) program. The SADABS (v2014/5) program [4-2] was used to correct for Lorentz and polarization effects and for absorption due to the sample. For both forms the tentative space group was determined with the XPREP (v2014/2) program [4-2]. The SHELXTL (v2014/7) program suite [4-2] was used to solve the structure by intrinsic phasing method and to refine the solution by full-matrix least-squares calculations on $\mathrm{F}^{2}$.

An Oxford Cryosystems nitrogen cryostat (Cryostream Plus) was added to the equipment described above. This cryostat allowed XRSCD experiments to be carried out at $100 \mathrm{~K}$.

\section{Temperature High resolution X-ray powder diffraction (T-HR-XRPD)}

XRPD diagrams as a function of temperature were carried out with a PANalytical X'Pert Pro MPD powder diffractometer using the Bragg-Brentano (vertical $\theta-2 \theta$ configuration) parafocusing geometry coupled with an X'Celerator detector and an Anton-Paar TTK450 temperature chamber. A sealed copper anode X-ray tube was used, running at $45 \mathrm{kV}$ and $40 \mathrm{~mA}$ levels. An incident beam monochromator (Johansson type) produces pure $\mathrm{Cu}$ K $\alpha 1$ radiation $(\lambda=1.54060 \AA \hat{)}$. A thin layer of the product was deposited on a singlecrystal silicon wafer, cut out according to Si (510) crystallographic orientation that, by systematic extinction, impedes any Bragg reflection. Data were acquired isothermally from 278 to $423 \mathrm{~K}$ with a heating rate of $3 \mathrm{~K} / \mathrm{min}$ between data collections. Diagrams were recorded under the following conditions: a 3 to 40 degree scan with a $0.017^{\circ}$ step size [in 2 $\theta$ ] and a counting time of 500 seconds per step.

For each diagram as a function of temperature the X-CELL indexing program [5-4 = M. A. Neumann, J. Appl. Cryst., 2003, 36, 356] was used to determine crystal cell parameters that were then refined by a modified Pawley method [5-5 = G. E. Engel, S.Wilke, O. Konig, K. D. M. Harris, F. J. J. Leusen, J. Appl. Cryst., 1999, 32, 1169].

\section{Scanning Electron Microscopy}

Scanning electron microscopy photographs were obtained with a Hitachi tabletop microscope model TM1000 after gold metallization.

\section{Differential Scanning Calorimetry (DSC)}

Two types of DSC analyzers were used in this study: 1) TA Instrument analyzers based on heat flow technology, a Q1000 and a Q100 and 2) a PerkinElmer Pyris Diamond analyzer based on power compensation technology. The calorimeters were temperature-calibrated with indium and lead (onset temperatures of $429.8 \mathrm{~K}$ and $600.7 \mathrm{~K}$ respectively). Energy calibration was carried out with a certified indium calibration sample (melting enthalpy of $28.71 \mathrm{~J} \mathrm{~g}^{-1}$ ). The measurements were carried out at a rate of $5 \mathrm{~K} \mathrm{~min}^{-1}$ (from 293 to $465 \mathrm{~K}$ ) under a constant nitrogen stream of $55 \mathrm{~mL} \mathrm{~min}^{-1}$ (30 mL min ${ }^{-1}$ for the Perkin). Between 1.5 and $5 \mathrm{mg}$ of sample was placed in crimped, sealed aluminum sample pans.

Specimens were weighed with a balance sensitive to $0.001 \mathrm{mg}$ and heated at a $10 \mathrm{~K} \mathrm{~min}^{-1}$ rate in aluminum closed pans. 


\section{High-Pressure Differential Thermal Analysis (HP-DTA)}

HP-DTA measurements were carried out at a $2 \mathrm{~K} \mathrm{~min}^{-1}$ heating rate using an in-house built high-pressure differential thermal analyzer similar to Würflinger's apparatus [6-75-WUR] that operates between $298-473 \mathrm{~K}$ and $0-300 \mathrm{MPa}$. To make sure that in-pan volumes were free from residual air, specimens were mixed with an inert perfluorinated liquid (Galden ${ }^{\circledR}$, from Bioblock Scientifics, Illkirch, France) as a pressure-transmitting medium. The mixtures were sealed in cylindrical tin pans, typically containing about $40 \mathrm{mg}$ of sample. To verify that the perfluorinated liquid was chemically inactive and that it would not affect the melting temperature of each sample, DSC measurements were carried out with Galden ${ }^{\circledR}$-sample mixture using the TA Instruments Q100.

An in-house made high-pressure differential thermal analyzer (HP-DTA), similar to the apparatus previously built by A. Würflinger (6-75WUR) and working in the $298-473 \mathrm{~K}$ and $0-300 \mathrm{MPa}$ ranges, was used to measure the temperatures of fusion of unweighed specimens in cylindrical tin pans. To make sure that in-pan volumes were free from residual air, specimens were in-pan mixed with an inert perfluorinated liquid (Galden ${ }^{\circledR}$, from Bioblock Scientifics, France) before the pans were closed. HP-DTA scans were run on heating at a $2 \mathrm{~K}$ $\min ^{-1}$ rate.

\section{Vapor pressure measurements}

Vapor pressure measurements have been carried out isothermally in the $383-423 \mathrm{~K}$ range with a DVS Vacuum apparatus from Surface Measurements Systems, U. K., [7-ref SMS] using a Knudsen cell whose orifice had a diameter of 241 micrometers, measured with a scanning electron microscope.

\section{Results}

\subsection{Crystallization of the two polymorphs}

Single crystals were obtained from various solutions as indicated in Table 1. The last synthesis step of fumarate salt of 1,4-diazabicyclo[3.2.2] nonane-4-carboxylate (SSR180711c) is a purifying step. The chemical purity of the batch used to Form 1 and Form 2 crystallogenesis, Sanofi batch QT-00328, was controlled by HPLC and found at $99.7 \%$. The single crystals of form 1 and form 2 were obtained by slow evaporation of methanol and water respectively.

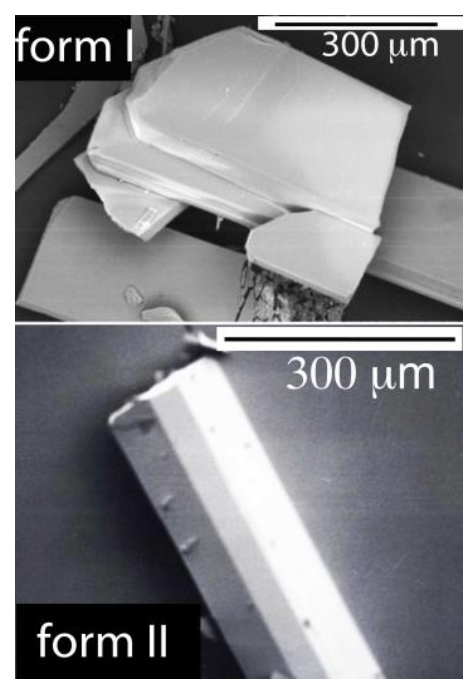


Figure 2. Scanning electron microscopy photographs of crystals of SSR180711C forms I and II.

In addition to these preliminary observations, and anticipating to the crystal structure determination, it was found that the crystals of form I are twinned (see Figure Sa in Supplementary material).

\subsection{Crystal structures}

Form 1: Several plate-like crystals were chosen and all were found to be twinned. The selected crystal was indexed as a two-component non merohedral twin using the CELL_NOW program [3-1]. The twin operator is a $180^{\circ}$ rotation about $c^{*}$. The reflections from the two domains were simultaneously integrated with the SAINT program [4-2]. The TWINABS program [5-3] was used to carry out adsorption corrections and to produce the HKLF 5 format file for final refinement of both twin domains. The space group determined using XPREP was $P 21 / c$. All hydrogen atoms were located on a Fourier difference map and subsequently included in the refinement with one overall isotropic thermal parameter. The final least-squares refinement of 330 parameters against 4590 data resulted in residuals $\mathrm{R}_{1}$ (for $4169 \mathrm{Fo}>4 \sigma(\mathrm{Fo})$ ) and $\mathrm{wR}_{2}$ (for all data) of 0.026 and 0.066 , respectively. The structure converged with nearly equal mass twin components (BASF $=0.54$ ), see Table 2 for details.

One hydrogen atom of fumaric acid is found located on the external $\mathrm{N}$ atom of the diazabicyclo-nonane group of the ssr180711 molecule $(\mathrm{dN}-\mathrm{H}=0.96 \AA)$. This indicates the salt nature of SSR180711c compound in form I solid state.

Form 2: A plate-like crystal was selected and indexed using APEX2 suite. The reflections were integrated with the SAINT program. The SADABS program was used to carry out adsorption corrections. The space group determined using XPREP was $P 2_{1} / n$. All hydrogen atoms were located on a Fourier difference map and subsequently included in the refinement with one overall isotropic thermal parameter. The final least-squares refinement of 329 parameters against 4519 data resulted in residuals $\mathrm{R}_{1}$ (for 4335 Fo > $4 \sigma(\mathrm{Fo})$ ) and $\mathrm{wR}_{2}$ (for all data) of 0.019 and 0.065 , respectively, see Table 2 for details. One hydrogen atom of fumaric acid is found located on the external $\mathrm{N}$ atom of the diazabicyclo-nonane group of the ssr180711 molecule ( $\mathrm{dN}-\mathrm{H}=0.89 \AA$ ). This indicates the salt nature of SSR180711c compound in form 2 solid state.

X-ray crystallographic information files (CIF) of forms 1 and 2 can be found in the Supporting Information. Crystallographic information files are also available from the Cambridge Crystallographic Data Center (CCDC) upon request (http://www.ccdc.cam.ac.uk).

Table 2. Crystal and experimental data for SSR180711c Form I and Form II

Form I

Chemical formula

$\mathrm{C}_{14} \mathrm{H}_{19} \mathrm{Br}_{1} \mathrm{~N}_{2} \mathrm{O}_{2}, \mathrm{C}_{4} \mathrm{H}_{2} \mathrm{O}_{4}$

441.28
Form II

$$
\mathrm{C}_{14} \mathrm{H}_{19} \mathrm{Br}_{1} \mathrm{~N}_{2} \mathrm{O}_{2}, \mathrm{C}_{4} \mathrm{H}_{2} \mathrm{O}_{4}
$$


Temperature (K)

Crystal system

Space group

$a(\AA)$

$b(\AA ̊)$

$c(\AA)$

$B\left(^{\circ}\right)$

Volume $\left(\AA^{3}\right)$

Z

$D_{\text {calc }}\left(\mathrm{g} / \mathrm{cm}^{3}\right)$

$\mu($ Mo $K \alpha)\left(\mathrm{mm}^{-1}\right)$

$F(000)$

Crystal size $\left(\mathrm{mm}^{3}\right)$

Radiation

20 range for data collection

Reflections collected

Independent reflections

No. parameters

Goodness-of-fit on $\mathrm{F}^{2}$

Final $R$ indexes $[I>=2 \sigma(I)]$
$100(2)$

$100(2)$

monoclinic

$P 2_{1} / c$

20.763(3)

$6.9443(10)$

$12.6877(18)$

$97.988(2)$

1811.6(5)

4

1.618

2.308

904.0

904.0

$0.04 \times 0.15 \times 0.30$

$0.04 \times 0.15 \times 0.50$

$\operatorname{MoK} \alpha(\lambda=0.71073)$

$\left[R_{\text {int }}=0.039, R_{\text {sigma }}=0.038\right] \quad\left[R_{\text {int }}=0.013, R_{\text {sigma }}=0.011\right]$
3.962 to $56.54^{\circ}$

12910

4590

330

329

1.035

1.143

2.78 to $58.192^{\circ}$

17988

4519

$\mathrm{R}_{1}=0.0261, \mathrm{wR}_{2}=0.0653$

$R_{1}=0.0193, w R_{2}=0.0558$ 
Conformation of SSR180711 molecules in Form 1 and Form 2: The molecular conformation of form I was found to be different from the molecular conformation of Form2 (see Figure YY). A $95^{\circ}$ twist of the aromatic ring was measured between both conformations.
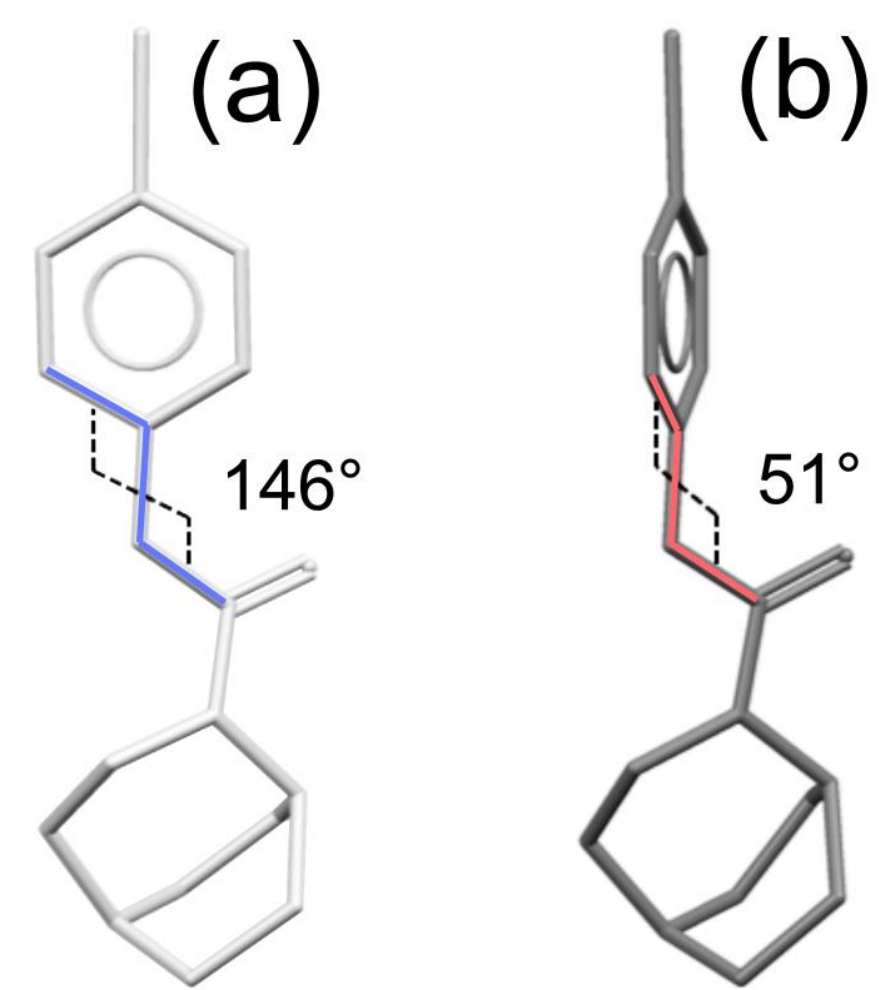

Figure 3: Molecular conformation of the SSR180711 ion in forms I (a) and II (b). Hatoms omitted for clarity. The change mainly consists in a difference of $95^{\circ}$ between the values of the dihedral angle between the phenyl ring and the rest of the molecule: $146^{\circ}$ in form 1 (blue) and $51^{\circ}$ in form 2 (red). 
Crystal packing of Form I and Form II: The two polymorphs exhibit different crystal packings (see Figures 4 and 5). Furthermore the intermolecular bonds in solid state of Form I and Form II differ entirely. Indeed Form I shows a 2D sub-structure with $(1,0,0)$ crystallographic orientation: a structure of bi-layers of SSR180711 ions separated by a mono-layer of H-bond-connected fumaric acid molecules. Within the core of the bi-layer, SSR180711 ions hydrophobically pack head to tail sharing both strong $\pi-\pi$ stacking intermolecular interactions between aromatic rings (parallel displaced configuration) and 3 weak $\mathrm{H}$-bonds between aromatic hydrogens and the carbonyl oxygen, leaving the hydrophilic SSR180711 part (ammonium salt hydrogen) pointed outward of both sides of the bi-layer. A strong hydrogen bond between the carboxylate of the fumaric acid and the ammonium part of SSR180711 provides the cohesion between the SSR180711 bilayer and the fumaric acid layer $\left(\mathrm{d}_{\mathrm{N} . . . \mathrm{O}}=2.67 \AA\right.$ and $\left.\mathrm{a}_{\mathrm{N}-\mathrm{H} \ldots \mathrm{O}}=165^{\circ}\right)$. Form II shows a $1-\mathrm{D}$ like sub-structure in $(0,1,0)$ direction: SSR180711 ions pack head to tail sharing a strong $\pi-\pi$ stacking intermolecular interactions between aromatic rings ( $\mathrm{T}$-shaped configuration) in a columnar distribution surrounded by two other similar SSR180711 columns and 4 columns of $\mathrm{H}$-bond-connected fumaric acid molecules. A strong hydrogen bond between the carboxylate of the fumaric acid and the ammonium part of SSR180711 brings cohesion between SSR180711 columns and fumaric acid columns $\left(\mathrm{d}_{\mathrm{N} \ldots \mathrm{O}}=2.73 \AA\right.$ and $\left.\mathrm{a}_{\mathrm{N}-\mathrm{H} \ldots \mathrm{O}}=176^{\circ}\right)$.

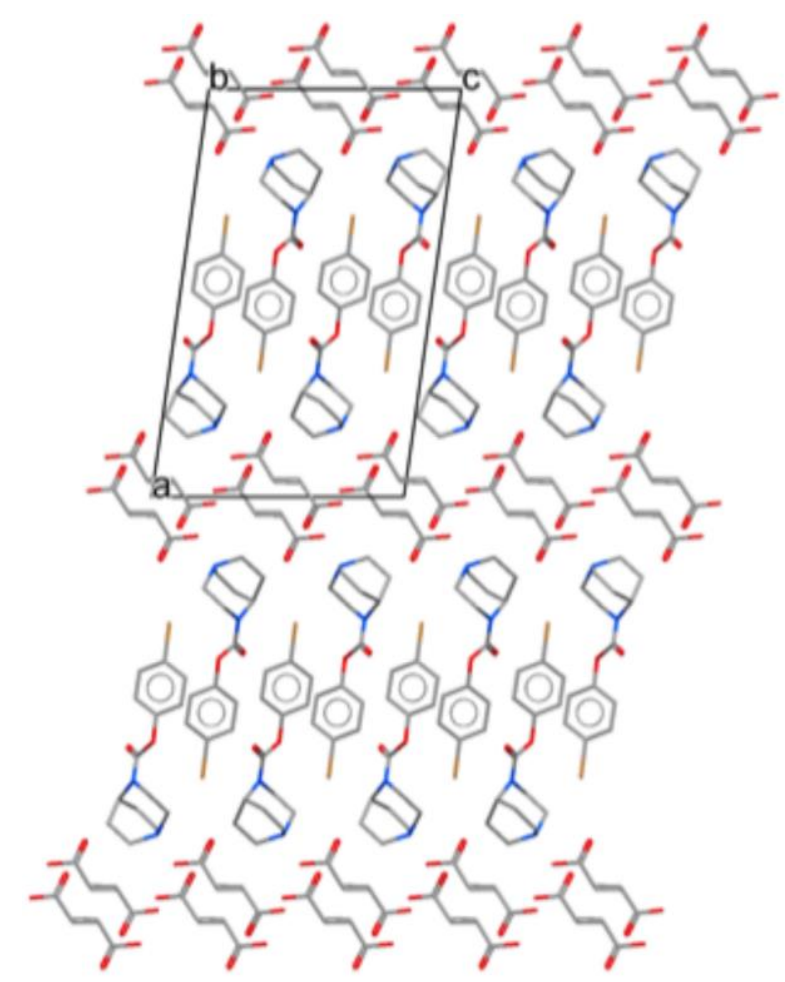

Figure 4: Crystal packing of form I (view along direction $\boldsymbol{b}$ ), H- atoms omitted. 


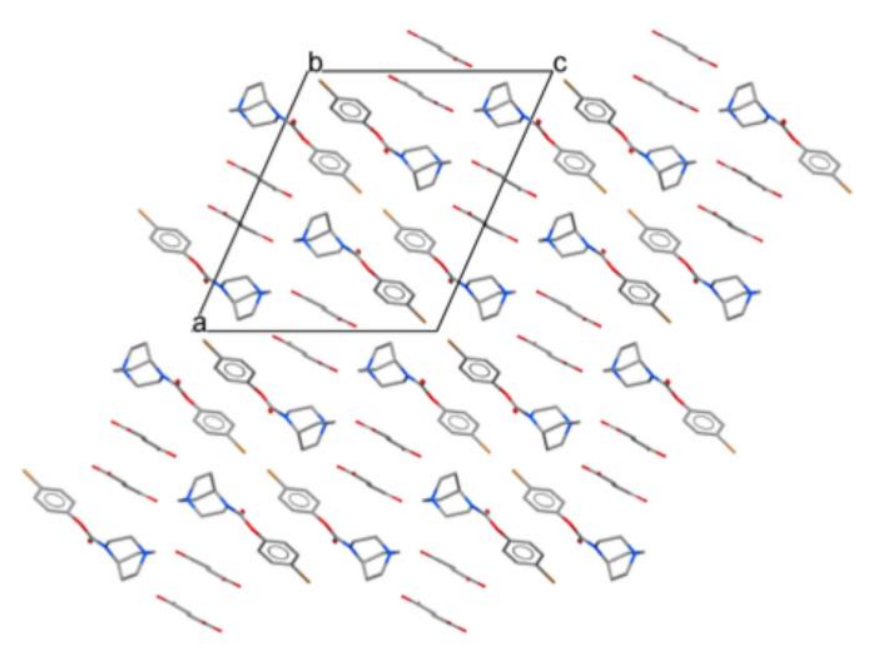

Figure 5: Crystal packing of form II (view along direction $\boldsymbol{b}$ ), H- atoms omitted.

\section{b.- Thermal expansions}

Lattice parameters and related data from Pawley fits [8-PAW] are compiled in supplementary Table S1, and the dependence of the specific volumes on the temperature is shown in Figure T1.

It can be seen that :

$1 /$ the difference in the specific volumes in the $278-423 \mathrm{~K}$ range is virtually independent of the temperature,

$\begin{array}{ll}\mathrm{v}(\mathrm{I}) / \mathrm{cm}^{3} \mathrm{~g}^{-1}=0.51109+\left(8.0233 * 10^{-5} * \mathrm{~T} / \mathrm{K}\right), \mathrm{r}^{2}=0.9966, & \text { Equation (1) } \\ \mathrm{v}(\mathrm{II}) / \mathrm{cm}^{3} \mathrm{~g}^{-1}=0.51230+\left(8.9016^{*} 10^{-5} * \mathrm{~T} / \mathrm{K}\right), \mathrm{r}^{2}=0.9993, & \text { Equation (2) }\end{array}$

$2 /$ if the values determined at $100 \mathrm{~K}$ from single crystals are taken into account, the specific volumes in $\mathrm{cm}^{3} \mathrm{~g}^{-1}$ as a function of temperature (in $\mathrm{K}$ ) are better described by quadratic functions :

$\mathrm{v}(\mathrm{I})=0.51994+2.856210^{-5}+7.365810^{-8} \mathrm{~T}^{2}\left(\mathrm{r}^{2}=0.9995\right)$, $\mathrm{v}(\mathrm{II})=0.52086+3.919910^{-5}+7.107410^{-8} \mathrm{~T} 2\left(\mathrm{r}^{2}=0.9998\right)$.

$3 /$ In the $278-423 \mathrm{~K}$ range the expansivities are close to each other: $\alpha_{\mathrm{V}}(\mathrm{I})=1.57 * 10^{-4} \mathrm{~K}^{-1}$, and $\alpha_{\mathrm{V}}(\mathrm{II})=1.74 * 10^{-4} \mathrm{~K}^{-1}$.

\section{Calorimetric studies.}

Only the fusion was observed on heating each form after controlling by thermogravimetry that the weight loss for specimens in pierced pans was negligible at the melting temperature. Temperatures (onsets) and heats of fusion obtained from 60 runs at a $10 \mathrm{~K} \mathrm{~min}^{-1}$ rate are compiled in supplementary Table S2. The mean values for the temperatures and heats of fusion are reported in Table $\mathbf{C 1}$.

\begin{tabular}{|l|l|l|l|l|l|}
\hline & $\begin{array}{l}\text { Min-max } \\
\text { values }\end{array}$ & $\begin{array}{l}\text { Number } \\
\text { of points }\end{array}$ & $\begin{array}{l}\text { Mean } \\
\text { value }\end{array}$ & $\begin{array}{l}\text { Standard } \\
\text { deviation }\end{array}$ & $\begin{array}{l}\text { Standard error } \\
\text { of the mean }\end{array}$ \\
\hline $\mathrm{T}_{\text {fus }}(\mathrm{I}) / \mathrm{K}$ & $447.87-448.22$ & 31 & 448.02 & 0.10 & 0.018 \\
\hline$\Delta_{\text {fus }} \mathrm{H}(\mathrm{I}) / \mathrm{J} \mathrm{g}^{-1}$ & $106.10-109.20$ & 31 & 107.41 & 0.93 & 0.17 \\
\hline
\end{tabular}




\begin{tabular}{|l|l|l|l|l|l|}
\hline $\mathrm{T}_{\text {fus }}(\mathrm{II}) / \mathrm{K}$ & $446.48-447.04$ & 29 & 446.68 & 0.12 & 0.022 \\
\hline$\Delta_{\text {fus }} \mathrm{H}(\mathrm{II}) / \mathrm{J} \mathrm{g}^{-1}$ & $107.80-111.80$ & 29 & 109.63 & 0.96 & 0.18 \\
\hline
\end{tabular}

Table C1. Temperatures (onset) and heats of fusion of the two forms of drug SSR18077C.

In addition, after quenching the melt from either of the two forms to room temperature, a glass transition was observed at $322 \mathrm{~K}$ (midpoint) without further recrystallization.

To confirm that the fusion of form II occurs at a temperature smaller than that of form II, crystals of each forms have been placed on a glass slide and observed by thermomicroscopy on heating at a $2 \mathrm{~K} \mathrm{~min}^{-1}$ rate under a nitrogen flux. Photographs taken in the T-range under which both meltings occur unambiguously indicate that form II melts at a temperature slightly smaller than that of form I. Photographs at various temperatures are shown in supplementary information (Figure Sa)

\section{3.- Dependence of the melting temperatures on the pressure.}

The onset temperatures of fusion as a function of pressure in the range from ordinary pressure to about $20 \mathrm{MPa}$ are compiled in Table P1.

\begin{tabular}{|l|l|l|l|}
\hline $\mathrm{P}(\mathrm{I}) / \mathrm{MPa}$ & $\mathrm{T}(\mathrm{I}) / \mathrm{K}$ & $\mathrm{P}(\mathrm{II}) / \mathrm{MPa}$ & $\mathrm{T}(\mathrm{II}) / \mathrm{K}$ \\
\hline 0,0000 & 447,15 & 0,0000 & 445,65 \\
\hline 38,630 & 458,75 & 43,230 & 454,35 \\
\hline 52,490 & 462,15 & 73,730 & 462,35 \\
\hline 87,800 & 470,25 & 91,770 & 467,15 \\
\hline 95,000 & 472,15 & 59,140 & 458,55 \\
\hline 26,940 & 455,35 & 28,770 & 452,45 \\
\hline 71,060 & 465,65 & 13,320 & 447,45 \\
\hline 19,930 & 452,65 & - & - \\
\hline
\end{tabular}

Table P1. Melting temperatures (onset) of SSR18077C forms I and II at various pressures.

According to the values compiled in Table P1, it can be shown that the melting curves of forms I and II can be described by straight lines (in the P-range investigated) and that they diverge on increasing the pressure, according to the following equations:

Pfus $(\mathrm{I}) / \mathrm{MPa}=-1732+3.68675 * \mathrm{~T} / \mathrm{K}\left(\mathrm{r}^{2}=0.99483\right) \quad$ Equation (3)

Pfus(II)/MPa $=-1873.4+4.2108 * \mathrm{~T} / \mathrm{K}\left(\mathrm{r}^{2}=0.99322\right) \quad$ Equation (4)

\section{4. - Vapor pressure measurements on forms I and II.}

Two series of measurements of the sublimation pressure as a function of temperature have been run on forms I and II, leading to the results compiled in Table P2.

\begin{tabular}{|c|l|l|l|l|}
\hline $\mathrm{T} / \mathrm{K}$ & \multicolumn{2}{|c|}{$\mathrm{P}_{\text {sub }}(\mathrm{I}) / \mathrm{Pa}$} & \multicolumn{2}{c|}{$\mathrm{P}_{\text {sub }}(\mathrm{II}) / \mathrm{Pa}$} \\
\hline 383,00 & 0,154 & - & 0,146 & - \\
\hline 388,00 & 0,249 & 0,286 & 0,374 & 0,355 \\
\hline 393,00 & 0,604 & 0,452 & 0,739 & 0,720 \\
\hline 398,00 & 0,939 & 1,250 & 1,410 & 1,400 \\
\hline 403,00 & 1,740 & 1,710 & 2,500 & 2,290 \\
\hline
\end{tabular}

Table P2. Vapor (sublimation) pressures of SSR18077C forms I and II in the T-range from $383 \mathrm{~K}$ to $403 \mathrm{~K}$

Sublimation pressures as a function of temperature were fitted to $\left(\mathrm{P}_{\text {sub }}\right.$ in $\mathrm{Pa}$ and $\mathrm{T}$ in $\left.\mathrm{K}\right)$ : 

Ln $\mathrm{P}_{\text {sub }}(\mathrm{I})=48.733-(19400 / \mathrm{T}), \mathrm{r}^{2}=0.980$,
Equation (5)
$\operatorname{Ln} \mathrm{P}_{\text {sub }}(\mathrm{II})=53.305-(21097 / \mathrm{T}), \mathrm{r}^{2}=0.994$.
Equation (6)

\section{Discussion}

As far as the structures are concerned, the location of one hydrogen atom from fumaric acid to a nitrogen atom of SSR180711 is shown in both polymorphs.

As far as the calorimetric information is concerned, it can be seen from Table $\mathbf{C 1}$ that both forms exhibit very close thermal behaviors. Nevertheless, it can be concluded that:

$1 /$ Form I melts at a temperature greater by about $1 \mathrm{~K}$ than the melting temperature of form II, 2 / the heat of fusion of form I is smaller by about $2 \mathrm{~J} \mathrm{~g}^{-1}$ than that of form II.

It can thus be inferred that the transition from form II to form I should be endothermic with a positive enthalpy change $\Delta_{\mathrm{II} \rightarrow \mathrm{I}} \mathrm{H}$ of $2.22 \mathrm{~J} \mathrm{~g}^{-1}$. This indicates that it should spontaneously occur on heating, according to the Le Chatelier principle.

In addition, if the volume change is taken into account, the endothermic transition of form II to form I should be accompanied with a negative volume change since the specific volume of form I is found to be smaller than that of fom II. Therefore it may be inferred that the $\mathrm{dP} / \mathrm{dT}$ slope of the I-II equilibrium curve should be negative, i.e. that the temperature of transition $\mathrm{II} \rightarrow \mathrm{I}$ should decrease as the pressure increases.

As far as the influence of the pressure is concerned, triple point I-II-liq should be observed at the crossing point of curves I-liq and II-liq, i.e. at negative pressure. This is made possible when the condensed phases are expanded, thus counteracting the force with which they are expanded. By equalizing equations (3) and (4), the coordinates of triple point I-II-liq are found to be T(I-II-liq) $=411.88 \mathrm{~K}$ and $\mathrm{P}(\mathrm{I}-\mathrm{II}-\mathrm{liq})=-139.06 \mathrm{MPa}$.

Indeed, such a triple point is metastable as it is located on the metastable counterpart of the stable I-liq line. Nevertheless, the I-II equilibrium curve should pass through this triple point since they share two common phases.

It is worth mentioning that this curve should also pass through triple point I-II-vap that can be located from sublimation pressure measurements. Making equal equations (5) and (6), its pressure and temperature are found to be $2.93 \mathrm{~Pa}$ and $371.2 \mathrm{~K}$, respectively.

This temperature should correspond to transition II $\rightarrow$ I at "ordinary" pressure that was not observed experimentally. However its temperature can be calculated by the method popularized by $\mathrm{Yu}[\mathbf{9 - Y \mathbf { u }}]$, based on the statement that, at the temperature of the I-II equilibrium, the entropy change $\Delta_{\mathrm{II} \rightarrow \mathrm{I}} \mathrm{S}$ equals the difference $\Delta_{\mathrm{I} \rightarrow \mathrm{liq}} \mathrm{S}-\Delta_{\mathrm{II} \rightarrow \mathrm{liq}} \mathrm{S}$ in the melting entropies. Using the temperatures and heats of fusion of forms I and II in Table C1, and neglecting the specific heats, the value $\mathrm{T}(\mathrm{I}-\mathrm{II}-\mathrm{vap})=390.2 \mathrm{~K}$ is obtained in the vicinity of the experimental value of $371.2 \mathrm{~K}$ found for the temperature of triple point I-II-vap.

How the temperature of any solid-solid transition depends on the pressure is generally represented in the P-T diagram by a straight line, at least in the pressure range under consideration in the present case. Regarding the I-II equilibrium curve, it equation corresponds to the straight line that crosses triple points I-II-liq and I-II-vap whose P,T coordinates are known : $\mathrm{P}(\mathrm{I}-\mathrm{II}) / \mathrm{MPa}=1268.9-3.4184 * \mathrm{~T} / \mathrm{K}$. 
This gives the P-T diagram shown in Figure 6, which corresponds to the second case of P,T representation of dimorphism described by Bakhuis Roozeboom [10-BR]: the case of overall enantiotropy in which lines I-II, I-liq and II-liq diverge on increasing the pressure,

independent of the sign of the $\mathrm{dP} / \mathrm{dT}$ slope of line I-II, which is negative in the present case.

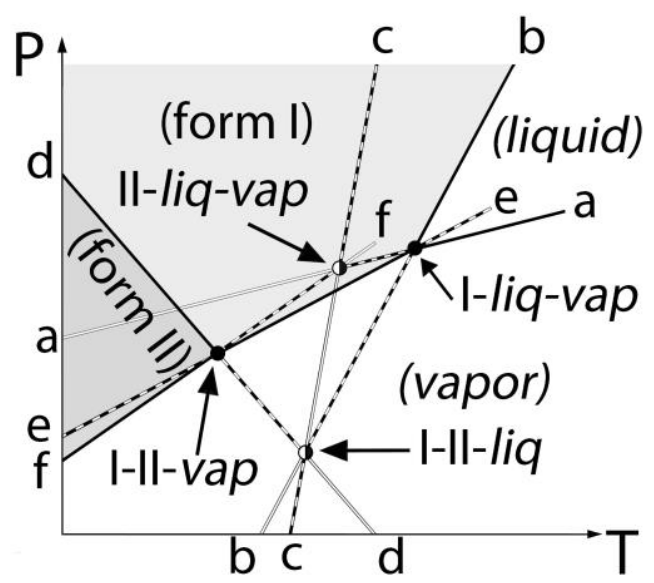

Figure 6. Topological P-T diagram for the dimorphism of SSR180711C.

Light and dark grey: stable phase regions for forms I and II, resp.. Two-phase equilibrium curves: $\mathrm{a}=$ liquid (liq)-vapor (vap), $\mathrm{b}=\mathrm{I}$-liq, $\mathrm{c}=\mathrm{II}$-liq, $\mathrm{d}=\mathrm{I}$-II, e = I-vap, f = II-vap.

Stability hierarchy: black segments $=$ stable, black and white segments = metastable, white segments $=$ super-metastable. Black points $=$ stable triple points, black and white points $=$ metastable triple points.

As a control, a topological construction of the P-T diagram may be drawn by means of the Clapeyron equation with the usual assumption following which the ratio $\mathrm{v}_{\text {liquid }} / \mathrm{v}_{\text {solid }}$ between the specific volumes of the liquid and the solid at the higher melting temperature is worth 1.11 (for a review, see ref. 11).

With $\mathrm{v}(\mathrm{I})=0.547036 \mathrm{~cm}^{3} \mathrm{~g}^{-1}$ at $\mathrm{T}_{\text {fus }}(\mathrm{I})$ given by equation (1), this leads to $\mathrm{v}_{\text {liquid }}=0.607210$ $\mathrm{cm}^{3} \mathrm{~g}^{-1}$ and $\Delta_{\mathrm{I} \rightarrow \mathrm{liq}} \mathrm{V}=0.060174 \mathrm{~cm}^{3} \mathrm{~g}^{-1}$ at $\mathrm{T}_{\text {fus }}(\mathrm{I})$. After incorporating this value together with Tfus(I) and $\Delta_{\text {fus }} \mathrm{H}(\mathrm{I})$ in the Clapeyron equation $\mathrm{dP} / \mathrm{dT}=\Delta \mathrm{H} / \mathrm{T} * \Delta \mathrm{v}$, the slope $\mathrm{dP} / \mathrm{dT}$ (I-liq) is found to be $3.984 \mathrm{MPa} \mathrm{K}^{-1}$, i.e. a value that compares well to the experimental one of 3.687 $\mathrm{MPa} \mathrm{K}^{-1}$ (equation 3).

As regards the II-liq melting curve, the same value as for form I may be used for the specific volume of the melt from form II at Tfus(II) since there is a small difference of only about $2^{\circ}$ in the melting temperatures. With this assumption, $\Delta_{\mathrm{II} \rightarrow \mathrm{liq}} \mathrm{V}=0.055148 \mathrm{~cm}^{3} \mathrm{~g}^{-1}$ at $\mathrm{T}_{\text {fus }}$ (II) using $\mathrm{v}(\mathrm{II})=0.552062 \mathrm{~cm}^{3} \mathrm{~g}^{-1}$ at this temperature from equation (2). The slope $\mathrm{dP} / \mathrm{dT}$ (II-liq) is thus found to be $4.450 \mathrm{MPa} \mathrm{K}^{-1}$, near its experimental value of $4.211 \mathrm{MPa} \mathrm{K}^{-1}$ (equation 4).

It is also worth mentioning that, the volume change on melting can be determined for each form using the experimental values of the slopes $\mathrm{dP} / \mathrm{dT}$ of their melting curves.

It comes to $\Delta \mathrm{v}(\mathrm{I}-$ liq $)=0.0650284$ and $\Delta \mathrm{v}$ (II-liq $)=0.05828654$ which lead, using the value of each specific volumes at each $\mathrm{T}_{\text {fus }}$ from equations 1 and 2 , to vliq/v(I) $=1.12$ at $\mathrm{T}_{\text {fus }}(\mathrm{I})$ and $\mathrm{vliq} / \mathrm{v}(\mathrm{II})=1.11$ at $\mathrm{T}_{\text {fus }}(\mathrm{II})$, i.e. very close to the previously determined average value of 1.11 [11].

\section{Concluding remarks.}

The crystal structures of two polymorphs of the 1:1 fumarate salt of 1,4-diazabicyclo[3.2.2]nonane-4-carboxylic acid 4-bromo-phenyl ester have been solved and the phase relationships between these two phases have been established through experimental and 
topological P-T state diagrams leading to the conclusion that forms I and II are in an overall enantiotropic relationship. The I-II equilibrium curve exhibits a negative $\mathrm{dP} / \mathrm{dT}$ slope. At ordinary pressure, the transition from fthe low-temperature form II to the high-temperature form I has been found to occur at $371 \mathrm{~K}$, the temperature at wich the experimental sublimation curves cross.

\section{References}

[1] B. Biton, O.E Bergis, F. Galli, A. Nedelec, A. W Lochead, S. Jegham, D. Godet, C. Lanneau, R. Santamaria, F. Chesney, J. Léonardon, P. Granger, M. W Debono, G.

A Bohme, F. Sgard, F. Besnard, D.Graham, A. Coste, A. Oblin, O. Curet, X. Vigé, C. Voltz, L. Rouquier, J. Souilhac, V. Santucci, C. Gueudet, D. Françon, R. Steinberg, G. Griebel, F. Oury-Donat, P. George, P. Avenet, B. Scatton.

SSR180711, a Novel Selective alpha7 Nicotinic Receptor Partial Agonist: (I) Binding and Functional Profile.

Neuropsychopharmacology (2007) 32(1), 1-16.

[2] P Pichat, OE Bergis, JP Terranova, A Urani, C Duarte, V Santucci, C Gueudet, C. Voltz, R Steinberg, J Stemmelin, F Oury-Donat, P Avenet, G Griebel, B Scatton.

SSR180711, a novel selective alpha7 nicotinic receptor partial agonist: (II) efficacy in experimental models predictive of activity against cognitive symptoms of schizophrenia. Neuropsychopharmacology (2007) 32(1), 17-34.

[3-1] G.M. Sheldrick, CELL_NOW Indexing Program for Twinned Crystals, Bruker AXS, Inc., Madison, Wisconsin, USA, 2008.

[4-2] A.X.S. Bruker, SAINT and XPREP are part of the APEX2 Software Suite for Crystallographic Programs, Bruker AXS, Inc., Madison, WI, USA, 2014. G.M. Sheldrick, (2008), Acta Cryst. A64, 112-122

[5-3] G.M. Sheldrick, TWINABS Bruker AXS Scaling for Twinned Crystals, Bruker AXS, Inc., Madison, Wisconsin, USA, 2012.

[5-4] M. A. Neumann

$X$-Cell: a novel indexing algorithm for routine tasks and difficult cases J. Appl. Cryst., 2003, 36, 356-365.

[5-5] G. E. Engel, S.Wilke, O. Konig, K. D. M. Harris, F. J. J. Leusen

PowderSolve - a complete package for crystal structure solution from powder diffraction patterns

J. Appl. Cryst., 1999, 32, 1169-1179.

(6-75WUR) Würflinger A 1975. Differential thermal-analysis under high-pressure.4. Lowtemperature DTA of solid-solid and solid-liquid transitions of several hydrocarbons up to 3 kbar.

Berichte Der Bunsen-Gesellschaft-Physical Chemistry Chemical Physics 79(12):1195-1201.

[7-ref SMS] http://surfacemeasurementsystems.com/products/dvs-instruments/dvs-vacuum/ 
[8-PAW] G. S. Pawley. EDINP, the Edinburgh powder profile refinement program J. Appl. Cryst. (1980). 13, 630-633.

[9-Yu ] Yu L. Inferring Thermodynamic Stability Relationship of Polymorphs from Melting Data. J Pharm Sci. 1995;84(8):966-74.

[10-BR] Bakhuis Roozeboom HW. Die heterogenen Gleichgewichte vom Standpunkte der Phasenlehre. Erstes Heft: Die Phasenlehre - Systeme aus einer Komponente. Braunschweig: Friedrich Vieweg und Sohn; 1901.

[11] R. Ceolin, I.B. Rietveld. The topological pressure-temperature diagram of ritonavir, an extraordinary case of crystalline dimorphism.

Ann. Pharm. Fr. 73, 2015, 22-30.

\section{Supplementary Information}

Table S1. Lattice parameters and specific volumes as a function of temperature from powder diffraction. Values in bold are from single crystals.

\begin{tabular}{|l|l|l|l|r|l|l|l|l|}
\hline \multicolumn{9}{|c|}{ Form I, monoclinic, $\mathrm{P} 2{ }_{1} / \mathrm{c}, \mathrm{Z}=4$} \\
\hline $\mathrm{T} / \mathrm{K}$ & $\mathrm{a} / \AA$ & $\mathrm{b} / \AA$ & $\mathrm{c} / \AA$ & $\beta /{ }^{\circ}$ & $\mathrm{V} / \AA$ & $\mathrm{v}^{\circ} \mathrm{cm}^{3} \mathrm{~g}^{-1}$ & $\mathrm{Rwp}$ & $\mathrm{Rp}$ \\
\hline 278.0 & 20.7782 & 7.0425 & 12.7678 & 98.5653 & 1847.47 & 0.5339 & 6.5 & 8.6 \\
\hline 298.0 & 20.7821 & 7.0541 & 12.7768 & 98.5733 & 1851.55 & 0.5350 & 3.8 & 5.3 \\
\hline 298.0 & 20.7812 & 7.0534 & 12.7706 & 98.5725 & 1851.08 & 0.5349 & 4.3 & 5.7 \\
\hline 298.0 & 20.7811 & 7.0535 & 12.7735 & 98.5639 & 1851.45 & 0.5350 & 6.6 & 8.8 \\
\hline 298.0 & 20.7813 & 7.0538 & 12.7731 & 98.5670 & 1851.47 & 0.5350 & 5.0 & 6.9 \\
\hline 323.0 & 20.7885 & 7.0703 & 12.7813 & 98.5685 & 1857.65 & 0.5368 & 3.8 & 5.5 \\
\hline 348.0 & 20.7935 & 7.0875 & 12.7920 & 98.5645 & 1864.18 & 0.5387 & 3.8 & 5.3 \\
\hline 373.0 & 20.8001 & 7.1071 & 12.7998 & 98.5573 & 1871.11 & 0.5407 & 3.6 & 5.3 \\
\hline 398.0 & 20.8009 & 7.1287 & 12.8086 & 98.5490 & 1878.37 & 0.5428 & 5.8 & 7.8 \\
\hline 408.0 & 20.8072 & 7.1382 & 12.8147 & 98.5369 & 1882.22 & 0.5439 & 5.1 & 7.0 \\
\hline 418.0 & 20.8115 & 7.1471 & 12.8177 & 98.5339 & 1885.42 & 0.5448 & 5.3 & 7.2 \\
\hline 423.0 & 20.8095 & 7.1524 & 12.8217 & 98.5311 & 1887.23 & 0.5454 & 5.4 & 7.2 \\
\hline $\mathbf{1 0 0}$ & $\mathbf{2 0 . 7 6 3}$ & $\mathbf{6 . 9 4 4 3}$ & $\mathbf{1 2 . 6 8 7 7}$ & $\mathbf{9 7 . 9 8 8}$ & $\mathbf{1 8 1 1 . 6}$ & $\mathbf{0 . 5 2 3 5}$ & & \\
\hline
\end{tabular}

\begin{tabular}{|l|l|l|l|l|l|l|l|l|}
\hline \multicolumn{10}{|c|}{ Form II, monoclinic, $\mathrm{P} 2_{1} / \mathrm{c}, \mathrm{Z}=4$} \\
\hline $\mathrm{T} / \mathrm{K}$ & $\mathrm{a} / \AA$ & $\mathrm{b} / \AA$ & $\mathrm{c} / \AA$ & $\beta /{ }^{\circ}$ & $\mathrm{V} / \AA$ & $\mathrm{v}^{\circ} \mathrm{cm}^{3} \mathrm{~g}^{-1}$ & $\mathrm{Rwp}$ & $\mathrm{Rp}$ \\
\hline 278.0 & 19.4792 & 6.4209 & 16.4729 & 115.5240 & 1859.26 & 0.5373 & 5.1 & 5.0 \\
\hline 298.0 & 19.4906 & 6.4238 & 16.4874 & 115.4060 & 1864.65 & 0.5388 & 5.1 & 5.0 \\
\hline 298.0 & 19.4859 & 6.4245 & 16.4845 & 115.4000 & 1864.16 & 0.5387 & 4.4 & 4.7 \\
\hline 323.0 & 19.5047 & 6.4285 & 16.5063 & 115.2540 & 1871.84 & 0.5409 & 4.0 & 4.6 \\
\hline 348.0 & 19.5232 & 6.4331 & 16.5296 & 115.1030 & 1879.95 & 0.5432 & 4.6 & 5.1 \\
\hline 373.0 & 19.5376 & 6.4373 & 16.5505 & 114.9280 & 1888.00 & 0.5456 & 3.8 & 4.1 \\
\hline 398.0 & 19.5497 & 6.4412 & 16.5732 & 114.7890 & 1895.27 & 0.5477 & 4.1 & 4.9 \\
\hline
\end{tabular}




\begin{tabular}{|l|l|l|l|l|l|l|l|l|}
\hline 408.0 & 19.5546 & 6.4432 & 16.5818 & 114.6730 & 1898.49 & 0.5486 & 4.2 & 5.1 \\
\hline 418.0 & 19.5615 & 6.4467 & 16.5914 & 114.6010 & 1901.78 & 0.5496 & 7.0 & 5.1 \\
\hline $\mathbf{1 0 0}$ & $\mathbf{1 9 . 0 2 3 1}$ & $\mathbf{6 . 4 0 0 5}$ & $\mathbf{1 6 . 3 4 9 2}$ & $\mathbf{1 1 3 . 9 9 5 0}$ & $\mathbf{1 8 1 8 . 6 0}$ & $\mathbf{0 . 5 2 5 5}$ & & \\
\hline
\end{tabular}

Table S2

Temperatures and heats of fusion of forms I and II (See also Figure S0).

\begin{tabular}{|c|c|c|c|}
\hline Tfus(I)/K(onset) & $\Delta_{\text {fus }} \mathrm{H}(\mathrm{I}) / \mathrm{J} \mathrm{g}^{-1}$ & Tfus(II)/K(onset) & $\Delta_{\text {fus }} \mathrm{H}(\mathrm{II}) / \mathrm{J} \mathrm{g}^{-1}$ \\
\hline 448.03 & 106.70 & 446.54 & 109.50 \\
\hline 448.01 & 106.40 & 446.66 & 110.20 \\
\hline 447.96 & 106.20 & 446.79 & 108.90 \\
\hline 448.09 & 107.80 & 446.61 & 109.30 \\
\hline 447.98 & 106.70 & 446.70 & 108.90 \\
\hline 447.93 & 109.00 & 446.52 & 109.30 \\
\hline 447.97 & 106.30 & 446.66 & 109.80 \\
\hline 448.07 & 108.30 & 446.48 & 109.10 \\
\hline 447.94 & 106.90 & 446.53 & 111.20 \\
\hline 448.10 & 108.90 & 446.70 & 110.80 \\
\hline 448.14 & 106.80 & 446.82 & 111.10 \\
\hline 448.01 & 106.80 & 446.67 & 107.80 \\
\hline 447.87 & 106.40 & 446.67 & 108.80 \\
\hline 448.03 & 106.90 & 446.59 & 108.70 \\
\hline 447.89 & 108.60 & 446.69 & 111.80 \\
\hline 447.93 & 108.30 & 446.74 & 108.20 \\
\hline 448.10 & 107.70 & 446.63 & 110.10 \\
\hline 447.99 & 106.40 & 446.61 & 110.20 \\
\hline 448.11 & 107.00 & 446.66 & 108.60 \\
\hline 448.22 & 109.20 & 446.63 & 110.40 \\
\hline 448.01 & 107.20 & 446.58 & 109.20 \\
\hline 447.89 & 107.30 & 446.70 & 109.40 \\
\hline 447.92 & 106.10 & 446.67 & 109.90 \\
\hline 448.13 & 108.10 & 446.83 & 110.20 \\
\hline 447.91 & 108.10 & 446.74 & 108.90 \\
\hline 447.95 & 107.20 & 446.93 & 111.00 \\
\hline 448.17 & 108.70 & 447.04 & 108.60 \\
\hline 448.11 & 106.50 & 446.69 & 109.50 \\
\hline 448.21 & 106.90 & 446.61 & 109.80 \\
\hline 448.15 & 108.30 & & \\
\hline 447.91 & 107.90 & & \\
\hline
\end{tabular}

Figure S0. Temperatures and heats of fusion of forms I (red circles) and II (blue squares) from values compiled in Table S2. 


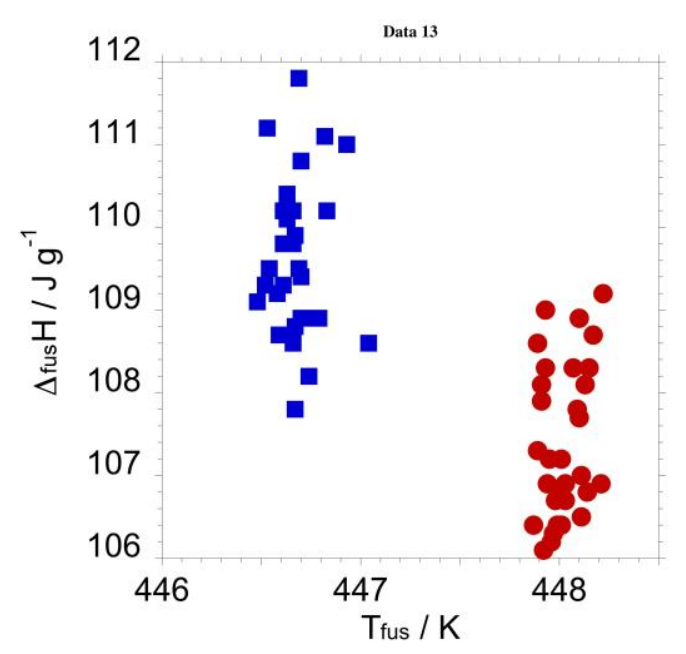

Figure Sa Optical microscopy photograph of twinned crystals of form I.

The photograp was taken with a Leica M420 Macroscope in polarized light. The black horizontal line measures 1 millimeter.

The arrow indicates where the "mille-feuille"-like twinning is visible. Colored areas on the plate at the left-hand side correspond to variants of the twinned crystal.

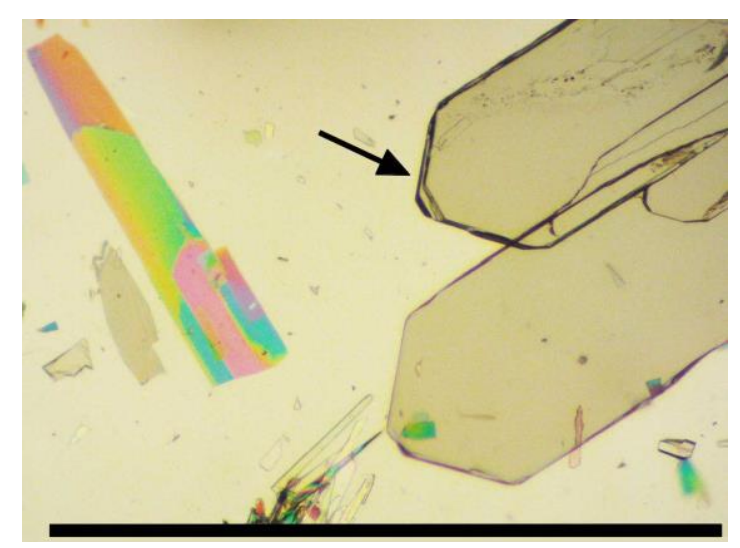

Figure Sb. Optical microscopy photographs of crystals of forms I (F I) and II (F II) taken with a DMRB microscope while heating at $2 \mathrm{~K} \mathrm{~min}^{-1}$ rate with a temperature controller Linkam TMS94 system.

It can be seen that form II melts at a smaller temperature than form I does. 


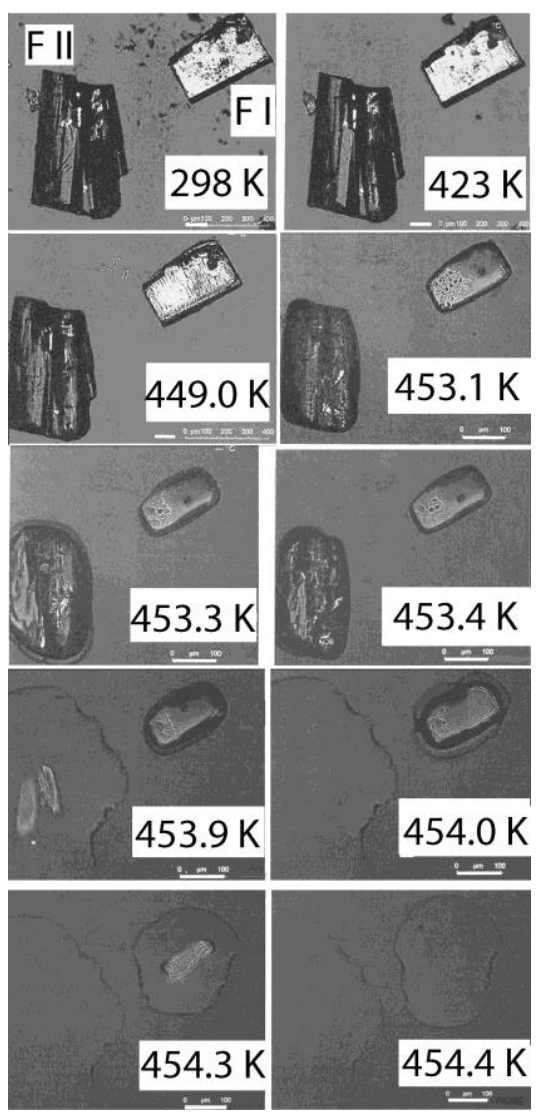

